\title{
Oxygation Improves Yield and Quality and Minimizes Internal Fruit Crack of Cucurbits on a Heavy Clay Soil in the Semi-arid Tropics
}

\author{
Surya P. Bhattarai (Corresponding author) \\ Centre for Plant and Water Science \\ Faculty of Sciences, Engineering and Health, CQUniversity \\ Rockhampton, QLD 4702, Australia \\ Tel: 61-7-4923-2140Ｅ-mail: s.bhattarai@cqu.edu.au \\ Jay Dhungel \\ Centre for Plant and Water Science \\ Faculty of Sciences, Engineering and Health, CQUniversity \\ Rockhampton, QLD 4702, Australia \\ Tel: 61-7-4930-6584Ｅ-mail: j.dhungel@cqu.edu.au
}

David J. Midmore

Centre for Plant and Water Science

Faculty of Sciences, Engineering and Health, CQUniversity

Rockhampton, QLD 4702, Australia

Tel: 61-7-4930-9770 E-mail: d.midmore@cqu.edu.au

The research is financed by CQUniversity Australia Merit Grant Scheme (Sponsoring information)

\begin{abstract}
Lack of oxygen due to sustained wetting fronts associated with drip and subsurface drip irrigated crops in heavy clay soil can negatively impacts on yield, fruit quality and water use efficiency of cucurbit crops. This study evaluated the effects of aerated irrigation water (oxygation) with subsurface drip irrigation, employing an in-line air injector (Mazzei venturi to introduce $12 \%$ air by volume of water) on fruit yield, quality and water use efficiency of watermelon (Citrullus vulgaris) and pumpkin (Cucurbita maxima) in a heavy clay soil. The fruit yield with oxygation increased from $14.5 \mathrm{tha}^{-1}$ to $24.6 \mathrm{tha}^{-1}$, and $26.3 \mathrm{t} \mathrm{ha}^{-1}$ to $28.9 \mathrm{t} \mathrm{ha}^{-1}$, for watermelon and pumpkin, respectively. The total soluble solids (TSS) increased by $19 \%$ with oxygation (13.2 vs. $11.1 \%$ ), and internal fruit crack decreased for watermelon, whereas in pumpkin fruit dry matter increased by $4 \%$ ( $40 \mathrm{vs.} 38.4 \%)$ and TSS by $7 \%$ (13.7 vs. $12.8 \%$ ). Season long water use efficiency was greater with oxygation compared to the control in both crops. The higher yield with oxygation was associated with a more rapid canopy cover, more leaf chlorophyll, and an increase in leaf photosynthetic rate, and leaf transpiration and an increase in fruit number and size. The results suggested that oxygation can ameliorate temporal hypoxia-associated with drip irrigated cucurbit crops in heavy clay soil and also offer yield and fruit quality benefits.

Keywords: Watermelon (Citrullus vulgaris), Pumpkin (Cucurbita maxima), Drip irrigation, Oxygation, Water use efficiency, Fruit internal crack, Fruit yield and quality

\section{Introduction}

Cucurbits are grown as irrigated crops for commercial production (Lee et al., 1995) as they are very responsive to irrigation. With escalating competition for water between industries, the access to and the cost of irrigation water become more critical. In Australia cucurbits are predominantly irrigated with micro irrigation such as sprinkler, drip irrigation (DI), and subsurface drip irrigation (SDI) (Kelly, 2007). For watermelon, the amount and timing of irrigation are important for efficient use of applied water and for maximizing crop yields and quality (Nischewitz et al., 2004). Cucurbit demand for water is relatively high compared to many other annual cereal and vegetable crops. Cucurbits irrigated with DI and SDI are generally irrigated for long durations at each irrigation event and frequently, particularly in the tropics and sub-tropics (McCann et al., 2007). Such crops tend to develop sustained wetting fronts especially in fine textured soils (Thabet and Zayani, 2008), which predisposes the rhizosphere to a
\end{abstract}


gradual lack of oxygen (hypoxia), leading to a deficit of oxygen in the root zone (anoxia). Most cucurbit crops are susceptible to wet foot and water-logging (Kato et al., 2001) predisposing the root system to various fungi causing root rot (Nischwitz et al., 2004; De Andrade-Junior et al., 1997).

We have termed such deprivation of oxygen after irrigation as an irrigation paradox - the hypoxic/anoxic root zone caused by irrigation has negative impacts on plant uptake of water and nutrients. Options to aerate irrigation water have been developed, and trialled for delivering water to the root zone to alleviate hypoxia, and such system using aerated water for DI and SDI has been referred to as oxygation (Bhattarai et al., 2008). We have measured the occurrence of hypoxia in the root zone of drip-irrigated crops in a range of soil types as it affects the performance in controlled environment experiments (Bhattarai et al., 2004). Previous research on drip irrigated zucchini in a loamy soil aerated with hydrogen peroxide at the rate of $5 \mathrm{~L} /$ ha at the end of each irrigation cycle increased yield and root biomass (Bhattarai et al., 2004). Benefits with oxygation have been recorded in different soil types, with variable response, in a number of crops largely grown under controlled environments in pots and in cotton in field conditions where planting density, therefore the root mass is comparatively higher (Bhattarai et al., 2008). This study examined the effect of oxygation on relatively wide spaced crops such as watermelon and pumpkin on their fruit yield, quality and water use efficiency (WUE)-expressed as fruit weight per megalitre of irrigation water, in a heavy clay soil in central Queensland, Australia. A better understanding of oxygation dynamics under field conditions in wide spaced crops and other factors influencing it could be helpful to clarify whether hypoxic conditions could occur in field-grown pumpkin and watermelon and how these crops respond to irrigation with oxygen-enriched irrigation water. The main aim of this work was to study, under commercial field crop of melon and pumpkin in the semi-arid tropics (i) the seasonal dynamics of the soil water and oxygen content, and (ii) the response to oxygen enrichment of the irrigation water on pumpkin and water melon crop growth, development, yield and quality on a heavy clay soil irrigated with aerated and non-aerated water.

\section{Materials and methods}

\subsection{Site and soil description}

Experiments on watermelon were conducted from Feb-June 2007 (summer towards winter) and on pumpkin from

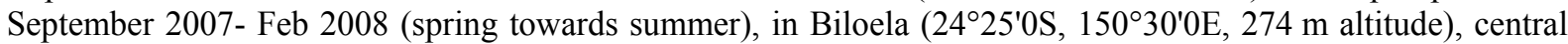
Queensland, Australia on a vertisol. The liquid limit (drop cone), plastic limit (rolling bead) and gravimetric water content values at $-1.5 \mathrm{MPa}$ (wilting point of $<2 \mathrm{~mm}$ sieved soil by pressure plate) in the $0-0.1 \mathrm{~m}$ layer were 56 , 22 and 17\% (volume/volume), respectively. The field site represents a Brigalow soil (Organic Matter 3.3\%) which is generally deep and heavy textured. The volumetric moisture content at field capacity and permanent wilting point for the surface soil (to $0.3 \mathrm{~m}$ depth) was $40 \mathrm{~mm}$ and $22 \mathrm{~mm} / 100 \mathrm{~mm}$ soil depth as determined by pressure plate apparatus following Richards (1949). The soil is slightly saline, and the irrigation water sourced from the deep bore recorded conductivity of $1200 \mu \mathrm{S} \mathrm{cm}^{-1}$, belonging to salinity class $\mathrm{C}_{2}$ (Anbazhagan and Nair, 2004) with sodium absorption ratio of 2.29 .

The site experiences hot summer day time conditions $\left(30-32^{\circ} \mathrm{C}\right)$ and mild winters $\left(23-25^{\circ} \mathrm{C}\right)$. The 10 year average (1996-2005) annual rainfall is $685 \mathrm{~mm}$ and evaporation was $1868 \mathrm{~mm}$. However, 2007 and early 2008 season were unusually dry (2007 rainfall $-490.5 \mathrm{~mm}$ ). A total rain of $71.5 \mathrm{~mm}$ and $164.5 \mathrm{~mm}$ was recorded during watermelon and pumpkin seasons, respectively (Figure 1). The average monthly maximum and minimum temperature decreased continuously during the melon crop but increased during the pumpkin season whereas relative humidity remained stable within the range of $57-69 \%$ (Figure 1).

\subsection{Experimental design and treatments}

The experiments were arranged in a randomized complete block design, comparing irrigation treatments (oxygation and a control - non-oxygation), also referred to as aerated and non-aerated irrigation water delivered through an SDI system with seven and six replications for watermelon and pumpkin, respectively. Each experimental unit comprised $200 \mathrm{~m}$ row lengths and $9 \mathrm{~m}$ plot width accommodating 3 rows/plot. Plants were spaced at $3 \mathrm{~m}$ row to row $\times 1 \mathrm{~m}$ plant to plant, and $3 \mathrm{~m}$ row to row $\times 0.9 \mathrm{~m}$ plant to plant orientation, accommodating 600 and 666 plants/plot of watermelon (including pollinators) and pumpkin respectively. The plots received either oxygation (aerated water $c .12 \%$ air in the form of bubbles) or control (non-aerated) drip irrigation throughout the crop with treatment imposed at an early establishment stage (when the seedlings reached a pair of true leaves) in both crops.

The drip tape (T-systems $16 \mathrm{~mm}$ pressure compensating-T 500) placed at the depth of $10 \mathrm{~cm}$, emitter flow rate of $170 \mathrm{~L} \mathrm{~h}^{-1}$ per $100 \mathrm{~m}$ length at $0.068 \mathrm{MPa}$ operating pressure. Dripper and lateral spacing were chosen to match between-row spacing of $3.0 \mathrm{~m}$ and $0.3 \mathrm{~m}$ between the emitters in the tape according to the soil characteristics and crop row spacing. The desired level of air in the aerated irrigation water was introduced by Mazzei air injector (Model 2081 and 3090-Mazzei injector Corp, USA), the pressure differential of which was adjusted to introduce 
$12 \%$ air by volume of water. The decision of when and how much to irrigate was based on the rate of soil moisture depletion and replenishments were done regularly. Both treatments were designated to receive $100 \%$ of daily crop evapotranspiration (ETc) in the vegetative stage and irrigation was applied when $50 \%$ of available soil moisture was depleted at $20-30 \mathrm{~cm}$ depth in the root zone. To accelerate fruit ripening and increase sugar content, irrigation was gradually reduced from potential daily crop irrigation requirements to deficit irrigation for all treatments (Motes, 1996). The melon crop received a total of 37 irrigations (2-7 hours cycle depending on crop water use), whereas the pumpkin crop received 21 irrigations (2-5 hours cycles) during the crop season.

\subsection{Crop management}

Lefroy Valley seedless watermelon hybrid variety Pinto F1 and pollinator variety Side Kick were planted (3:1) on 16 February 2007 and South Pacific Seeds pumpkin variety Kens Special Hybrid 864 was planted on 12 September 2007. The ground was treated with 5 micron lime power $\left(50 \mathrm{~kg} \mathrm{ha}^{-1}\right)$ as ground spray before planting and mulching. All field practices including fertilizer applications and insect and disease management were as recommended for the region (Motes, 1996). $175 \mathrm{~kg} / \mathrm{ha}$ each of sulphate of ammonia and muriate of potash was applied as a basal dose whereas side dressing comprised $100 \mathrm{~kg}$ calcium nitrate, $40 \mathrm{~kg}$ sulphate of ammonia, $30 \mathrm{~kg}$ potassium nitrate, 50 $\mathrm{kg}$ potassium sulphate and $10 \mathrm{~kg}$ zinc sulphate per hectare.

\subsection{Measurements}

\subsubsection{Weather and soil water content}

Weather data were sourced from the nearby Biloela airport Bureau of Meteorology (BOM). Soil water contents were determined in each plot by a micro-gopher (offset $10 \mathrm{~cm}$ from emitter), a capacitance probe (Odyssey Data Flow system Pvt. Ltd, New Zealand) in $0.1 \mathrm{~m}$ increments from 0 to $0.9 \mathrm{~m}$ depth at sowing, and at weekly intervals during the growth of each crop until final harvest. ETc was calculated using the soil water balance method for the growing season and for individual growth periods (Heerman, 1985). Since the amount of irrigation water applied was only sufficient to bring the water deficit to field capacity, drainage was included in the water budget analysis. Crop applied water was calculated as the sum of daily irrigation water and any rainfall input to the soil during the crop season (irrigation+rain).

\subsubsection{Crop physiological parameters}

Effects of irrigation treatments on reproductive performance including days to first flowering, peak flowering, fruit set and start of harvest were recorded. Data recording on physiological parameters was carried out during flowering in five sample plants in each plot for the leaf chlorophyll content using a SPAD meter (Konica Minolta, Japan), leaf gas exchange (photosynthesis, stomatal conductance, leaf transpiration rate using an ADC LCA-4 (ADC BioScientific Ltd, England) and specific leaf area (SLA) following the procedures by Garnier et al. (2001). Canopy cover by the crop was assessed based on the measurement in a $1 \mathrm{~m}^{2}$ grid following the procedure by Haverkort et al. (1991).

\subsubsection{Fruit yield and quality}

The number and weight of marketable fruits (i.e. minimum quality standards set by Woolworth for water melon) and unmarketable fruits were harvested in a sample area $(10 \mathrm{~m}$ row length/plot $)$ and whole plot harvest was carried out by the industry at the end of the crop season (May-June for melon and Jan-Feb for pumpkin respectively). On every harvest, three marketable fruits per plot were selected randomly for fruit traits (size, shape and rind thickness) and quality analysis. The total soluble solids content (TSS) of the juice of the inner tissue was measured with a refractometer on melon flesh samples $(\sim 10 \mathrm{~g}$ each) from four equatorial positions in the cross section of each watermelon (Kato, 1997). These values were then averaged and presented as percentage TSS.

Dry matter content (\%), fruit flesh density and flesh colour were also quantified. Marketable yield was determined by counting and weighing the fruits that passed the marketing criteria. In watermelon, the density of the fruit was determined by the volume displacement method (Fernández-Trujillo et al., 2005) using a precision balance $( \pm 1 \mathrm{~g})$. The degree of hollowness volume was determined following Diezma-Iglesias et al. (2004) by pouring water into the watermelon cavity such that it penetrated not only the larger cavity but also the small holes spaced around seeds. The scoring for cavity was: $0=$ no crack, $1=25 \mathrm{ml}, 10=250 \mathrm{ml}$ of water taken by the cavity.

\subsubsection{Water use efficiency}

The water use efficiency (WUE) was calculated as instantaneous water use efficiency $\left(\mathrm{WUE}_{\mathrm{i}}\right)$ and season long water use efficiency $\left(\mathrm{WUE}_{\mathrm{sl}}\right)$. The $\mathrm{WUE}_{\mathrm{sl}}$ was calculated as fresh fruit yield (total) divided by crop applied water (plus rainfall and the net soil moisture extracted from the soil). The $W_{U E}$ was calculated from the Infra Red Gas Analyser (IRGA) data such that the photosynthetic net assimilation was divided by leaf transpiration rate. 


\subsection{Statistical analyses}

Standard analysis of variance was carried out for all data using GenStat Edition 11. When treatment effects were significant $(P<0.05)$, pair-wise comparison of means was tested using least significant differences (LSD). All significant differences in the text are for $P<0.05$ unless otherwise stated. The regression analysis modeled the expected value of dependent variable $y$, fruit density, in terms of the value of an independent variable (or vector of independent variables) $x$, scoring for internal fruit crack. Modeling the density of fruits in terms of the variation in the internal fruit crack, the density decreased by increasing amounts for each unit of increase in internal cavity, hence a quadratic model best fitted in these data.

\section{Results}

\subsection{Applied water and soil moisture distribution}

The contribution of rainfall to crop water requirement was minimal in both crops (71 and $161 \mathrm{~mm}$ for melon and pumpkin respectively). There were six and eight rainfall events exceeding $5 \mathrm{ml}$ of rainfall (effective rain) for watermelon and pumpkin (Figure 1). Crop applied water was greater for the control compared to oxygation in both crops (for watermelon, 1.573 ML ha ${ }^{-1}$ vs. 1.446 ML ha ${ }^{-1}$, and pumpkin 1.364 $\mathrm{ML} \mathrm{ha}^{-1}$ vs. 1.229 ML ha ${ }^{-1}$ ). The oxygation dried soil (i.e. a greater water extraction) throughout the profile more than did the control (Figure 2) where soil moisture was generally above field capacity suggesting an hypoxic environment.

\subsection{Crop phenology}

There was no treatment effect on earliness measured by days to first flowering (76-78 das and 63-65 das for watermelon and pumpkin respectively) and days to first harvest (99-106 das and 84-91 das for watermelon and pumpkin respectively). However, oxygation extended the length of the total growing period (from date of seeding to final harvest) for watermelon by 21 days (104 to 125 das) and for pumpkin by 15 days (141 to 156 das).

\subsection{Physiological determinants}

The ground area cover by foliage increased by $11 \%$ (92 vs. 83\%) with oxygation for watermelon measured 45 das and by $13 \%$ ( 89 vs. $76 \%$ ) due to oxygation for pumpkin measured 63 das. The effect of oxygation on leaf chlorophyll concentration was also notable; SPAD readings were greater for oxygation in watermelon (52 vs. 47) and pumpkin (47 vs. 42), measured 71 and 86 das, respectively (Table 1). Root weight and root length density (RLD) with oxygation were also greater for both crops compared to the control when measured during early harvest (data not presented). However, the effect of oxygation on stem and leaf weight at final harvest were not significant in either crop. Leaf photosynthesis, leaf transpiration and stomatal conductance increased with oxygation compared to the control in watermelon but in pumpkin the differences between oxygation and control were not statistically significant. The specific leaf area (SLA) in both crops increased significantly with oxygation.

\subsection{Yield and yield attributes}

The total fruit yield of watermelon increased significantly with oxygation compared to the control (Figure 4) (24.6 vs. $14.5 \mathrm{t} \mathrm{ha}^{-1}$, SED $\left.(6 \mathrm{df})=3.57\right)$. Likewise total fruit number in the sample harvest was significantly greater for oxygation compared to the control $\left(4278 \mathrm{vs} .4056\right.$ fruits ha $^{-1}$, SED $\left.(6 \mathrm{df})=107\right)$. Weight and number

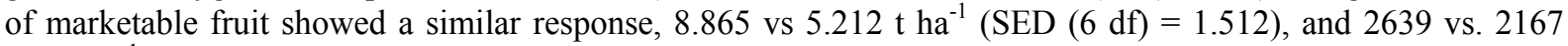
fruits ha ${ }^{-1}(\operatorname{SED}(6 \mathrm{df})=227)$ for oxygation and control respectively. The marketable fruits harvested were only one third of the total fruit load of the crop (fruits later in the season were not harvested for market due to low prices.

In pumpkin the marketable fruit yield with oxygation was higher compared to the control (28.875 vs. $26.254 \mathrm{t}$ $\left.\mathrm{ha}^{-1} \mathrm{SED}(5 \mathrm{df})=1.987\right)$ but the difference was not statistically significant. Number of fruits harvested increased significantly with oxygation compared to the control (14410 vs. $13100 \mathrm{ha}^{-1}$ SED $\left.(5 \mathrm{df})=418\right)$.

\subsection{Fruit quality}

The TSS content of the watermelon at final harvest (Figure 3) was significantly greater with oxygation (13.25 vs. $11.1^{\circ}$ Brix). Likewise, in pumpkin both dry matter content (40 vs. $38.4^{\circ}$ Brix) and TSS (13.7 vs. $12.8^{\circ}$ Brix) increased with oxygation, both significant at $\mathrm{P} \leq 0.05$. The proportion of fruits with internal crack decreased significantly with oxygation for watermelon (Figure 3 ). A preliminary analysis linked the internal crack score with densitometry in a negative polynomial relationship (Figure 4).

\subsection{Water use efficiency}

The $\mathrm{WUE}_{\mathrm{sl}}$ of watermelon and pumpkin fruit production (Figure 3) increased by $80 \%$ (11.412 vs. $6.351 \mathrm{ML}^{-1}$ and $16 \%\left(10.171\right.$ vs. $\left.8.823 \mathrm{t} \mathrm{ML}^{-1}\right)$ respectively with oxygation. However, the instantaneous water use efficiency $\left(\mathrm{WUE}_{\mathrm{i}}\right)$ for neither crop differed significantly between treatments (Table 1). 


\section{Discussion}

Oxygation did not influence days to flowering in either crops. However, in a previous experiment oxygation hastened flowering in tomato (Bhattarai et al., 2008), and there was an indirect indication of earlier maturity of pumpkin in another field trial (Bhattarai et al., 2008). Earlier flowering in soybean and cotton in pot trials has been noted with oxygation (Bhattarai et al., 2004). Of interest, with oxygation the crop duration was extended by 21 days for watermelon and 15 for pumpkin. Ookawa et al. (2001) established that the greater functionality of the root system, greater root length density and greener leaf surface (as noted by higher SPAD reading) reflected a slowed down senescence. The higher SPAD values in the current study recorded for oxygation are consistent with our earlier findings on tomato (Bhattarai et al., 2008), soybean, zucchini and cotton (Bhattarai et al., 2004), and associated increase (13-14\%) in canopy cover, measure by grid, during the flowering period with oxygation are consistent with our earlier work on other species.

The increase in leaf photosynthesis and transpiration was more prominent for watermelon and less notable for pumpkin. We have reported consistent effects of oxygation on leaf photosynthesis for a number of species such as tomato, soybean, and cotton and on pumpkin (Bhattarai et al., 2004). The lack of response in pumpkin was possibly due to the very dry summer season (Figure 1) and the response of leaf photosynthesis under water limited conditions to the higher light load through photo-inhibition. Photo-inhibition in cucurbits is common in a Mediterranean environment when the crop is exposed to stresses, e.g. high temperature and low soil moisture (Lichtenthaler and Burkart, 1999). Leaf gas exchange was measured only around midday, a time that largely coincides with mid-day depression of photosynthesis in the semi-arid tropics, particularly for crops grown under drip and SDI (Srinivas et al., 1989). Drip irrigated plants often have insufficient root volumes to meet the high canopy demand for transpiration (Pier and Doerge, 1995). However, the higher RLD with oxygation did not apparently offset this effect.

In pumpkin the yield increment with oxygation was $10 \%$. Lower pumpkin yields in the control were not only due to reduced fruit number but also to smaller fruit size. In a previous experiment with pumpkin in the field the yield increase by oxygation was likewise in the order of $15 \%$ by weight $\left(79.3 \mathrm{vs} .69 .0 \mathrm{t} \mathrm{ha}^{-1}\right)$ largely due to increase in fruit size in a relatively water-unstressed season (Bhattarai et al., 2008). Severe water stress at the fruit-filling stage for pumpkin did not allow all fruits to develop to the full potential size. Soil moisture readings for the rooting zone were noted below refill point at this stage (data not presented). Unmarketable fruits were not harvested, and about $25 \%$ of the yield was still left in the field. The yield of pumpkin with oxygation could be improved, for the number of fruit per vine was higher for oxygation during fruit set if the irrigation requirements were further matched to fruit development stage so that the crop does not face water stress (Pier and Doerge, 1995).

Internal fruit quality of watermelon is critical for marketing (Kato, 1997). We noted a positive effect of oxygation on reducing the internal crack of melon fruits (Figure 3). Although oxygation minimized the internal fruit crack, the cause of watermelon fruit internal crack is not yet known (Diezema Iglesias et al., 2004). Agronomic, physiological and genetic approaches towards mitigating this problem will help the melon industry significantly as the fruits with internal crack are unmarketable and causes significant economic loss to growers.

The yield increase in watermelon was consistent in small plot sampling and commercial harvest of the whole plot. Most of the yield increase was due to increased weight per fruit with oxygation $(5.75 \pm 1.39 \mathrm{~kg})$ compared to the control $(3.57 \pm 1.08 \mathrm{~kg})$ and not to the fruit number. The oxygation effect was very pronounced for dry matter content and degree Brix. Ozaki et al. (2009) also reported significantly greater degree Brix and melon yield with daily application of $300 \mathrm{ml} 20 \mathrm{mM} \mathrm{H}_{2} \mathrm{O}_{2}$ /plant in irrigation consistent with Bhattarai et al. (2008) on pumpkin and tomato where oxygation increased degree Brix and quality of fruits.

Less applied water was received by the oxygation than control treatments, by 9 and $11 \%$ for watermelon and pumpkin, respectively. The greater $\mathrm{WUE}_{\mathrm{sl}}$ for pumpkin and watermelon was, therefore, due to the greater yield per unit of water applied over the season and reduced water use. However, the yield response was proportionately greater for watermelon than pumpkin. High temperature and vapour pressure deficit during pumpkin fruit development stage caused great transpirational demand on plants, negatively affecting fruit growth. In field-grown pumpkin, we noted a $16 \%$ increase in $\mathrm{WUE}_{\mathrm{sl}}$ (Bhattarai et al., 2008) when the environmental conditions were milder. Less soil moisture was recorded for oxygated soil profile (Figure 2), suggesting greater increased root water uptake and transpiration. Gains in $\mathrm{WUE}_{\mathrm{sl}}$ of SDI compared to DI arise by curtailing soil evaporative loss (Dogan et al., 2008), and are likely to increase with oxygation.

The higher transpiration per unit leaf area, the greater canopy cover, and the longer crop duration with oxygation, all with less applied water (Table 1), suggests possible deep drainage in the control treatment. The soil profile at 30 $\mathrm{cm}$ and below in the control remained saturated most of the time (pre- and post-irrigation) compared to oxygation where the soil profile to $70 \mathrm{~cm}$ depth was mostly at or below FC (Figure 2). This is supported by the more visually 
reduced state of soil at similar depths when compared to oxygation. The results confirm that pumpkin and watermelons respond positively to oxygation for yield, fruit quality and $\mathrm{WUE}_{\mathrm{sl}}$. These results on both cucurbits are consistent with the results from zucchini trials where an increase in yield $(25 \%)$, water use efficiency and greater root growth were affiliated to aeration of the rhizosphere with hydrogen peroxide at the rate of $5 \mathrm{~L} /$ ha towards the end of irrigation cycle in a loamy soil (Huber, 2000). In both crops, increase in yield and water use efficiency was associated with greater light interception by canopy, leaf chlorophyll content, specific leaf area, and leaf gas exchange parameters except for $\mathrm{WUE}_{\mathrm{i}}$ and $\mathrm{PN} / \mathrm{g}_{\mathrm{s}}$

\section{References}

Anbazhagan, S., \& Nair, A. M. (2004). Geographic information system and groundwater quality mapping in Panvel Basin, Maharashtra, India. Environmental Geology, 45, 753-761.

Bhattarai, S. P., Huber, S. \& Midmore, D. J. (2004). Aerated subsurface irrigation water gives growth and yield benefits to zucchini, vegetable soybean and cotton in heavy clay soils. Annals of Applied Biology, 144, 285 298.

Bhattarai, S. P., Midmore, D. J. \& Pendergast, L. (2008). Yield, water-use efficiencies and root distribution of soybean, chickpea and pumpkin under different subsurface drip irrigations depths and oxygation treatments in vertisols. Irrigation Science, 26, 439 - 450.

De Andrade-Junior, A. S., Rodrigues, B. H. N., Athayde-Sobrinho, C., Melo, F. De B. \& Bastos, E. A. (1997).Yield and fruit quality in watermelon as affected by different irrigation levels. Horticultura Brasileira, 15 (1), $43-46$.

Diezema-Iglesias, B., Ruiz-Altisent, M. \& Orihuel, B. (2004). Detection of internal quality in seedless watermelon by acoustic impulse response. Biosystem Engineering, 88 (2), $221-230$.

Dogan, E., Kirnak, H., Berekatoglu, K., Bilgel, L. \& Surucu, A. (2008). Water stress imposed on muskmelon (Cucumis melo L.) with subsurface and surface drip irrigation systems under semi-arid climatic conditions. Irrigation Science, 26, $131-138$.

Fernández-Trujillo, J. P., Obando, J., Martínez, J. A., Alarcón, A., Eduardo, I., Monforte, A. J. \& Arús, P. (2005). Statistical multivariate analysis of melon shape: a case study using near isogenic lines. Acta Horticulturae, 674, $537-544$.

Garnier, E., Shipley, B., Roumet, C. \& Laurent, G. (2001). A standardized protocol for the determination of specific leaf area and leaf dry matter content. Functional Ecology, 15, 688 - 695.

Haverkort, A. J., Uenk, D., Veroude, H. \& Van De Waart, M. (1991). Relationships between ground cover, intercepted solar radiation, leaf area index and infrared reflectance of potato crops. Potato Research, 34, $113-$ 121.

Heerman, D. F. (1985). ET in irrigation management. In: Proceedings of the National Conference on Advances in Evapotranspiration. Transactions of the American Society of Agricultural Engineers, 323 - 334.

Huber, S. (2000). New uses of drip irrigation: Partial root zone drying and forced aeration. MSc thesis, Technische Universitat Munchen, Germany, 99pp.

Kato, D., Ohshima, N., Kamada, H., \& Satoh, S. (2001). Enhancement of the inhibitory activity for greening in xylem sap of squash root with water logging. Plant Physiology and Biochemistry, 39, $513-519$.

Kato, K. (1997). Electrical density sorting and estimation of soluble solids content of watermelon. Journal of Agricultural Engineering Research, 67, 161 - 170.

Kelly, G. (2007). Cucurbit production in Australia. Acta Horticulturae (ISHS), 731, 479 - 484

Lee, S. G., Lee, J. S., Kim, K. Y., Chung, J. H., Yoo, S. O. \& Bae, J. H. (1995). Effect of irrigation control on the quality and yield of watermelon (Citrullus vulgaris $\mathrm{S}$.) in high density staking cultivation under rain-shelter. RDA-Journal of Agriculture Science; Soil and Fertilizer, 37 (1), 245 - 249.

Lichtenthaler, H. K. \& Burkart, S. (1999). Photosynthesis and high light stress. Bulgarian Journal of Plant Physiology, 25, 3 - 16.

McCann, I., Kee, E., Adkins, J., Ernest, E. \& Ernest, J. (2007). Effect of irrigation rate on yield of drip-irrigated seedless watermelon in a humid region. Scientia Horticulturae, 113, $155-161$.

Motes, J. E. (1996). What influences sweetness in Cantaloupe. Vegetable Production and Marketing News, Texas Agricultural Extension Service, 6 (5), $1-4$. 
Nischewitz, C., Oslen, M. \& Rasmussen, S. (2004). Effect of irrigation type on inoculum density of Macrophomina phaseolina in melon fields in Arizona. Journal of Phytopathology, 152(3), 133 - 137.

Ookawa, T., Nishiyama, M., Takahiro, J., Ishihara, K. \& Hirasawa, T. (2001). Analysis of the factors causing differences in the leaf-senescence pattern between two soybean cultivars, Enrei and Tachinagaha - comparison of root length and exudation rate among grafted plants. Plant Production Science, 4(1), 3 - 8.

Ozaki, K., Uchida, A., Takabe, T., Shinagawa, F., Tanaka, Y., Takabe, T., Hayashi, T., Hattori, T., Rai, A. K. \& Takabe, T. (2009). Enrichment of sugar content in melon fruits by hydrogen peroxide treatment. Journal of Plant Physiology, 166 (6), $569-578$.

Pier, J. \& Doerge, T. A. (1995). Nitrogen and water interactions in trickle irrigated watermelon. Soil Science Society America Journal, 59 (1), 145-150.

Richards, L. A. (1949). Methods of measuring soil moisture tension. Soil Science, 68, 95 - 112.

Srinivas, K., Hegde, D. M. \& Havanagi, G. V. (1989). Irrigation studies on watermelon (Citrullus lanatus (Thunb.) Matsum et Nakai). Irrigation Science, 10, 293 - 301.

Thabet, M. \& Zayani, K. (2008). Wetting patterns under trickle source in a loamy sand soil of south Tunisia. American-Eurasian Journal of Agriculture an Environmental Science, 3(1), 38 - 42.

Table 1. Growth, water relations and gas exchange attributes of watermelon and pumpkin at 52 and 59 days subjected to oxygation and control. Means with the same letter acrosseach column and each attribute do not differ significantly at $\mathrm{p}=0.05(\mathrm{n}=5)$

\begin{tabular}{|c|c|c|c|}
\hline Parameters & Crop & Oxygation & Control \\
\hline \multirow{2}{*}{$\begin{array}{l}\text { Net photosynthetic rate }(\mathrm{PN})(\mu \mathrm{mol} \\
\left.\mathrm{m}^{2} \mathrm{~s}^{-1}\right)\end{array}$} & Watermelon & $17.4 \pm 1.32 \mathrm{a}$ & $13.0 \pm 1.26 \mathrm{~b}$ \\
\hline & Pumpkin & $22.4 \pm 1.64 \mathrm{a}$ & $20.4 \pm 1.59 \mathrm{a}$ \\
\hline \multirow{2}{*}{ 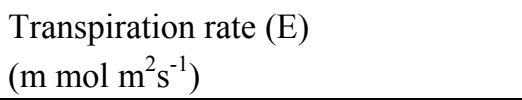 } & Watermelon & $4.1 \pm 0.23 \mathrm{a}$ & $3.1 \pm 0.19 \mathrm{~b}$ \\
\hline & Pumpkin & $4.2 \pm 0.26 \mathrm{a}$ & $3.8 \pm 0.21 \mathrm{a}$ \\
\hline \multirow{2}{*}{$\begin{array}{l}\mathrm{PN} / \mathrm{E}\left(\mathrm{WUE}_{\mathrm{i}}\right) \\
\left(\mu \mathrm{molCO}_{2} \mathrm{~m} \mathrm{~mol}^{-1} \mathrm{H}_{2} \mathrm{O}\right)\end{array}$} & Watermelon & $4.2 \pm 0.24 \mathrm{a}$ & $4.19 \pm 0.25 \mathrm{a}$ \\
\hline & Pumpkin & $5.3 \pm 0.23 \mathrm{a}$ & $5.36 \pm 0.31 \mathrm{a}$ \\
\hline \multirow{2}{*}{$\begin{array}{l}\text { Stomata conductance }\left(\mathrm{g}_{\mathrm{s}}\right) \\
\left(\mathrm{mol} \mathrm{m}^{2} \mathrm{~s}^{-1}\right)\end{array}$} & Watermelon & $0.10 \pm 0.002 \mathrm{a}$ & $0.10 \pm 0.002 b$ \\
\hline & Pumpkin & $0.18 \pm 0.003 \mathrm{a}$ & $0.14 \pm 0.002 b$ \\
\hline \multirow{2}{*}{$\begin{array}{l}\text { Season long WUE } \\
\left(\text { tonnes } \mathrm{ML}^{-1} \text { ) }\right.\end{array}$} & Watermelon & 11.4 & 6.3 \\
\hline & Pumpkin & 10.2 & 8.8 \\
\hline \multirow{2}{*}{$\begin{array}{l}\mathrm{PN} / \mathrm{g}_{\mathrm{s}} \\
\left(\mu \mathrm{molCO} \mathrm{mol} \mathrm{m}^{2} \mathrm{~s}^{-1}\right)\end{array}$} & Watermelon & $145 \pm 9.76 \mathrm{a}$ & $130 \pm 8.93 \mathrm{a}$ \\
\hline & Pumpkin & $124.4 \pm 8.23 \mathrm{a}$ & $145.7 \pm 9.02 \mathrm{a}$ \\
\hline \multirow{2}{*}{$\begin{array}{l}\mathrm{C}_{\mathrm{i}} / \mathrm{C}_{\mathrm{a}} \\
\left(\mu \mathrm{mol} \mathrm{m} \mathrm{s}^{-1}\right)\end{array}$} & Watermelon & $0.21 \pm 0.002 \mathrm{a}$ & $0.18 \pm 0.002 b$ \\
\hline & Pumpkin & $0.13 \pm 0.002 \mathrm{a}$ & $0.06 \pm 0.001 \mathrm{~b}$ \\
\hline \multirow[t]{2}{*}{ Leaf chlorophyll (SPAD) } & Watermelon & $47 \pm 2.07 \mathrm{a}$ & $42 \pm 2.13 \mathrm{~b}$ \\
\hline & Pumpkin & $44 \pm 1.31 \mathrm{a}$ & $41 \pm 1.37 \mathrm{~b}$ \\
\hline \multirow[t]{2}{*}{ Ground leaf cover (\%) } & Watermelon & $92 \pm 3.66 \mathrm{a}$ & $83 \pm 3.43 b$ \\
\hline & Pumpkin & $89 \pm 2.95 \mathrm{a}$ & $76 \pm 2.39 \mathrm{~b}$ \\
\hline \multirow[t]{2}{*}{ Total fruits (\#/ha) } & Watermelon & $4278 \pm 96 \mathrm{a}$ & $4056 \pm 82 \mathrm{~b}$ \\
\hline & Pumpkin & $14410 \pm 237 \mathrm{a}$ & $13100 \pm 185 b$ \\
\hline \multirow[t]{2}{*}{ Marketable fruit (\#/ha) } & Watermelon & $2639 \pm 126 \mathrm{a}$ & $2167 \pm 139 b$ \\
\hline & Pumpkin & & \\
\hline \multirow[t]{2}{*}{ Marketable yield (t/ha) } & Watermelon & $8.86 \pm 1.12 \mathrm{a}$ & $5.21 \pm 0.92 \mathrm{~b}$ \\
\hline & Pumpkin & $28.87 \pm 2.07 \mathrm{a}$ & $26.25 \pm 1.98 \mathrm{a}$ \\
\hline \multirow[t]{2}{*}{$\operatorname{SLA}\left(\mathrm{cm}^{2} \mathrm{~g}^{-1}\right)$} & Watermelon & $187 \pm 3.36 \mathrm{a}$ & $174 \pm 2.12 \mathrm{~b}$ \\
\hline & Pumpkin & $143 \pm 2.59 \mathrm{a}$ & $135 \pm 2.07 \mathrm{~b}$ \\
\hline
\end{tabular}




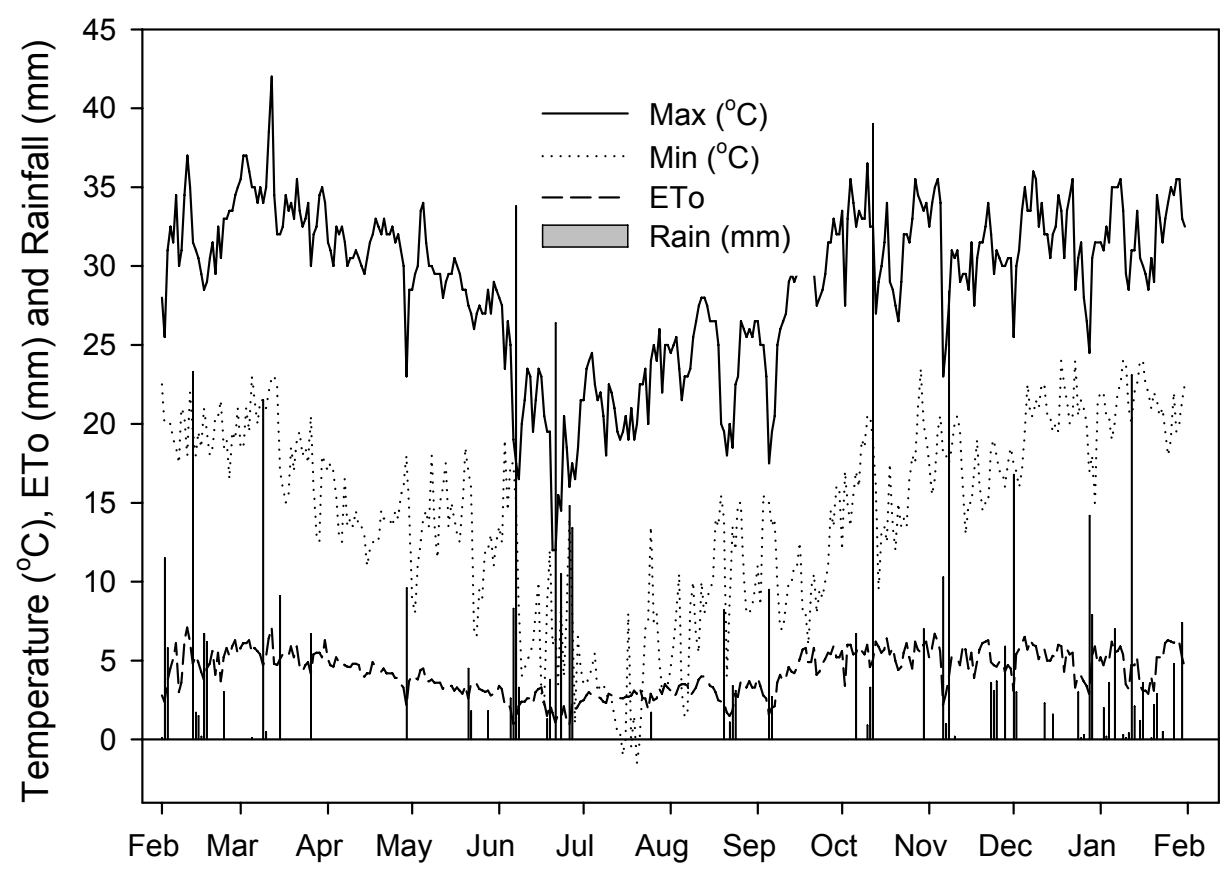

Figure 1. Daily maximum (solid thick line), minimum temperature (dotted thin line), reference crop evapo-transpiration (FAO 56-dotted thick line), and precipitation (vertical bar) during the crop period (2007) for Biloela, central Queensland, Australia

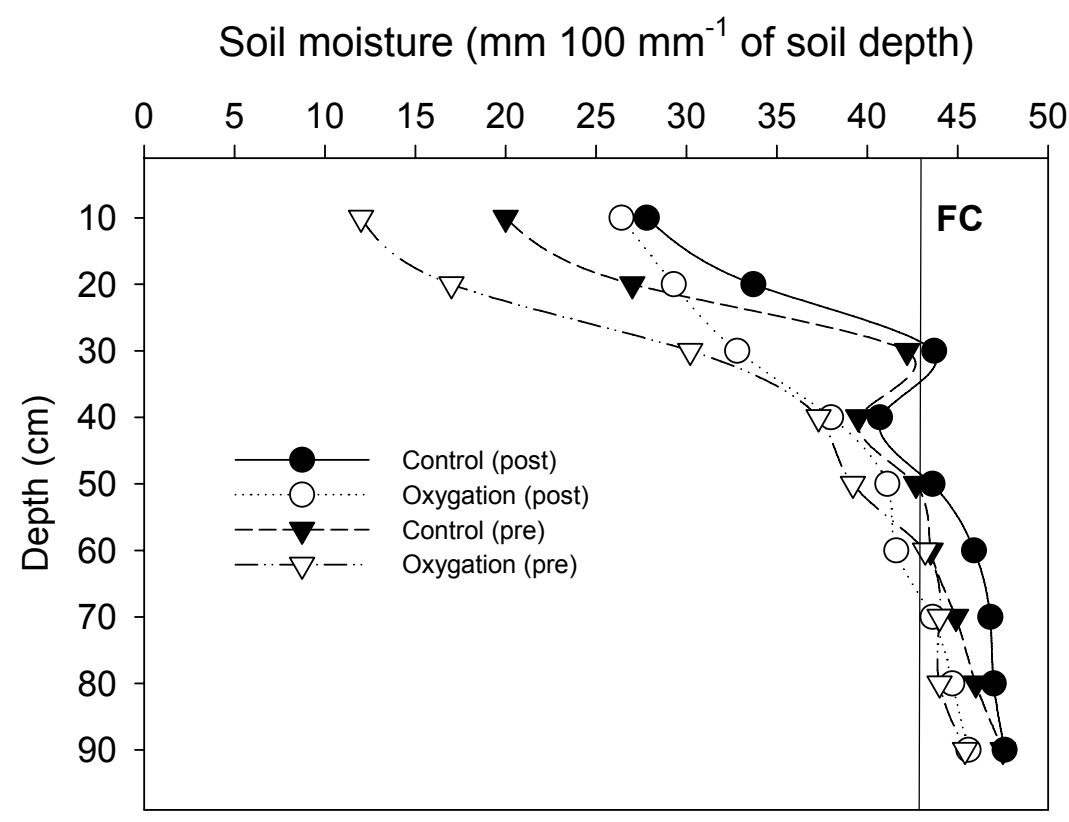

Figure 2. Soil moisture at various depths before (pre) and after (post) irrigation for watermelon in oxygation and control. FC denotes for the region of field capacity 


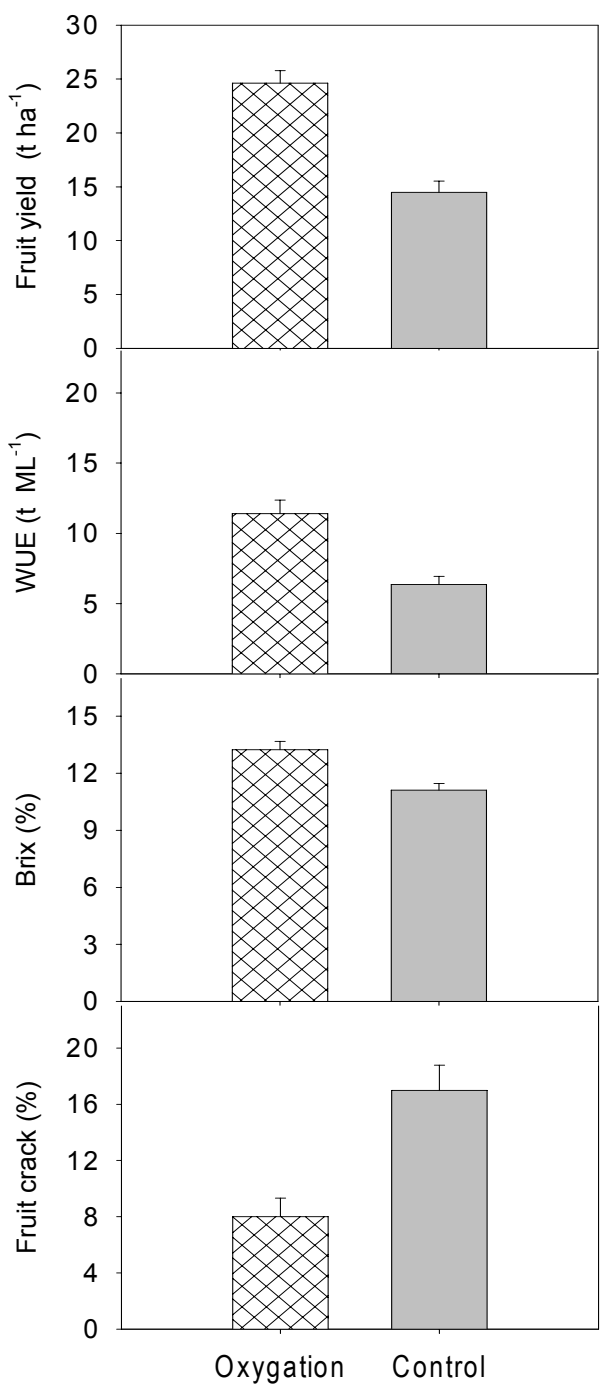

Figure 3. Watermelon total fruit yield, season long water use efficiency (WUE), ${ }^{\circ}$ Brix and fruit cracking as affected by oxygation and control (mean $\pm \mathrm{SE}$ ) at Biloela, Central Queensland, Australia,

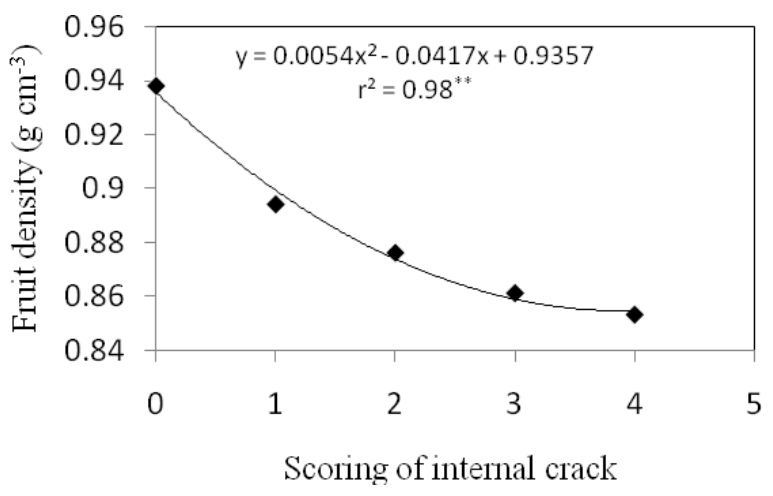

2007

Figure 4. Relationship between the intensity of fruit internal crack and density of fruits for watermelon grown in Biloela during 2007, QLD, Australia 